\title{
THERMAL PROTECTION TILE STRUCTURES OF SHUTTLECRAFT WITH DIFFERENT EXTERNAL LOAD-CARRYING ELEMENTS
}

\author{
V.G. TIKHY ${ }^{1}$, V.V. GUSEV ${ }^{1}$, A.M. POTAPOV ${ }^{1}$, E.I. SHEVTSOV ${ }^{1}$, I.A. GUSAROVA ${ }^{1}$, \\ T.A. MANKO ${ }^{2}$ and Yu.V. FALCHENKO ${ }^{3}$ \\ ${ }^{1}$ M.K. Yangel DB «Yuzhnoe» \\ 3 Krivorozhskaya Str., 49008, Dnepropetrovsk, Ukraine. E-mail: info@juzhnoye.com \\ ${ }^{2}$ O. Gonchar Dnepropetrovsk National University \\ 72 Yu. Gagarin Ave., 49050, Dnepropetrovsk, Ukraine \\ ${ }^{3}$ E.O. Paton Electric Welding Institute, NASU \\ 11 Bozhenko Str., 03680, Kiev, Ukraine. E-mail: office@paton.kiev.ua
}

\begin{abstract}
Thermal protection tile structures, made from heat-resistant materials, are widely applied for protection of space vehicle bodies. Carbon-carbon composite materials, high-temperature metal alloys and structural ceramics can be used as high-temperature heat-resistant materials for manufacturing thermal protection structure tiles. The presented work gives calculation-theoretical assessment of strength properties of combined tiles of thermal protection structure of returnable space vehicles, having a metal external load-carrying element and body from carbon-carbon composite material, as well as tiles from carbon-carbon and ceramic materials. The advantages and disadvantages of each of the studied thermal protection tile systems are considered. Strength analysis is used to determine the dimensions of load-carrying elements for bodies of thermal protection structures, meeting the requirements of strength, stability and resistance to flutter, and weight of each structure. It is found that thermal protection tiles with a body from carbon-carbon composite materials and tiles with an external three layer honeycomb panel from YuIPM-1200 alloy have the best weight and strength characteristics. 6 Ref., 5 Tables, 9 Figures.
\end{abstract}

$\boldsymbol{K} \boldsymbol{e} \boldsymbol{y} \boldsymbol{w} \boldsymbol{o} \boldsymbol{r} \boldsymbol{d} \boldsymbol{s}:$ returnable space vehicles, thermal protection tile structures, stress-strain state, carbon-carbon composite materials, high-temperature metal alloys

Tiles based on quartz fibers were used in returnable Space Shuttle and Buran vehicles-aircraft for thermal protection of sections, heated up to $1200{ }^{\circ} \mathrm{C}$. A serious drawback of quartz ceramic tiles is their extreme brittleness and low strength, as well as permanent joint of tile thermal protection with airframe skin. More attractive is the concept of removable thermal protection tile structures with the body of resistant materials and internal thermal insulation. Such a structure ensures a more reliable fastening of thermal protection tiles by mechanical means and convenience of their interflight maintenance.

Carbon-carbon composite materials (CCCM), heat-resistant metal alloys and structural ceramics can be used as high-temperature heat-resistant material of tiles of thermal protection structure (TPS). TPSs, the surface density of which does not exceed $10 \mathrm{~kg} / \mathrm{m}^{2}$, are acceptable [1].

Each of heat-resistant materials has its advantages and disadvantages. Metal advantages include the fact that their production is highly standardized and their quality is guaranteed within narrow tolerances. Here extremely important is the fact that extensive experience of transfer of metal sample testing results to full-scale structure parts has been accumulated. The main heat-resistant materials applied for operation in high-temperature structures, are iron- and nickelbased alloys. The main disadvantages of metals are their high specific weight and insufficient corrosion resistance at working temperatures.

Ceramic materials are essentially superior to metals and alloys by many service parameters (thermal stability, hardness, corrosion resistance, density, accessibility and low cost of raw materials). The main problems arising at selection of ceramics for TPS tiles are its inherent brittleness and possibility of catastrophic failure because of development of Griffith cracks [2,3].

CCCM are characterized by low weight, high strength and rigidity, and low coefficient of thermal expansion. Moreover, this material strength rises with temperature. CCCM preserve their mechanical properties at up to $500{ }^{\circ} \mathrm{C}$ temperatures in non-oxidizing media better than any other material. At application in thermal protection structures of space vehicles (SV) all the external surfaces from CCCM structures should be protected 


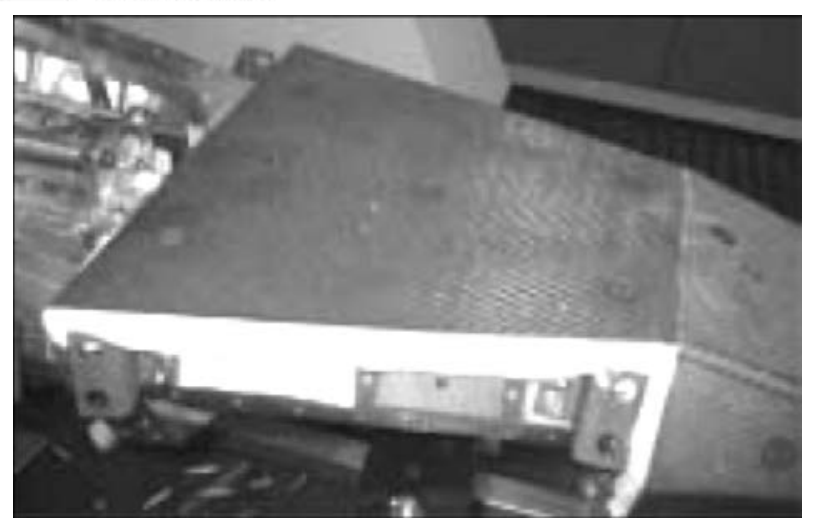

Figure 1. Panels from CCCM-SiC of DRL Company with internal thermal insulation

by heat- and erosion-resistant coating, preventing material loss in the atmospheric section of the flight [1]. DLR developed external heatresistant panels from $\mathrm{CCCM}-\mathrm{SiC}$ composite (Figure 1) [4].

Panels from such materials are used in TPSs of ISV SHEEFEX, PH HIFiRE 8 and IXV demonstrator [5]. Manufacturing CCCM structures is a lengthy and expensive process.

The objective of this work is comparative analysis of thermal protection tiles with an external load-carrying layer from various thermostable materials and internal thermal insulation pack, based on calculation-theoretical evaluation of their strength and weight characteristics.

The object of investigations are TPS tiles of for shuttlecraft with load-carrying element from metal, carbon-carbon and ceramic materials and internal thermal insulation. The studied TPSs should have surface density of not more than $10 \mathrm{~kg} / \mathrm{m}^{2}$, and ensure temperature lowering from $1100{ }^{\circ} \mathrm{C}$ on outer wall to $200{ }^{\circ} \mathrm{C}$ on inner wall within 20 min per one cycle of the vehicle intended use, while withstanding 100-fold repetition of such cycles for 15 years.

Analysis of currently available reusable TPSs showed that the main elements of removable thermal protection tiles are external load-carrying element from heat-resistant material, internal

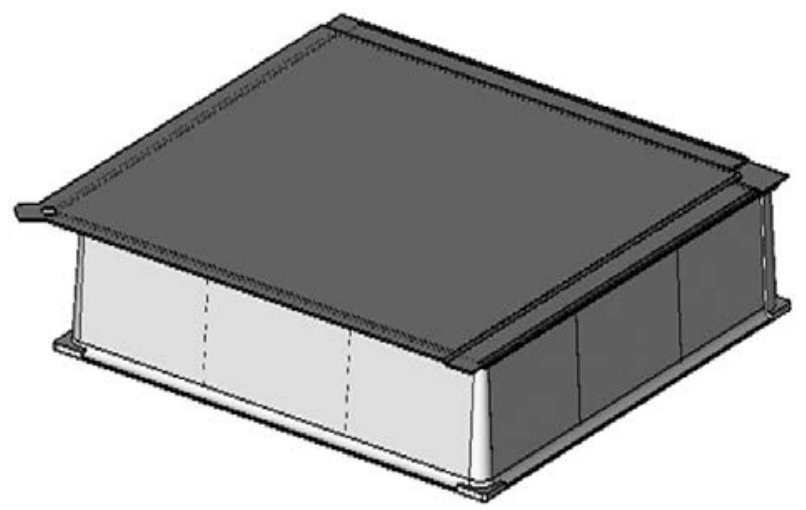

Figure 2. Design of combined thermal protection tile light-weight fibrous thermal insulation and system of fastening thermal protection tiles to SV load-carrying shell. Load-carrying element should have a structure, which develops minimal internal stresses at loading that allows reducing the thicknesses and, therefore, its weight.

In order to analyze the variants of external load-carrying element of various structures from a number of heat-resistant materials, a calculation-theoretical procedure was developed for evaluation of the influence of aerodynamic impacts on removable thermal protection tiles of shuttlecraft, based on MSC Nastran software package. Comparative analysis of structure variants was performed for tiles with in-plane dimensions of $300 \times 300 \mathrm{~mm}$ and $50 \mathrm{~mm}$ height of useful volume for placing the light thermal insulation material. Six different variants of tiles with bodies from CCCM and structural ceramics, with metal sheet, three-layer corrugated and honeycomb loadcarrying elements have been designed and analyzed, as well as combined tile with CCCM body and metal sheet load-carrying element.

Designs of tiles with metal sheet, three-layer corrugated and honeycomb load-carrying elements and results of calculation of their stressstrain state (SSS) are given in work [6].

Combined TPS tile consists of CCCM body and external metal load-carrying element, which is attached in eight points to the body ribs in the points of their intersection with side walls ( $\mathrm{Fi}^{-}$ gure 2).

Bodies of thermal protection tiles from CCCM and ceramics are made by an identical schematic and they are designed in the form of a whole formed box (Figure 3).

Tile body is reinforced by 4 ribs, separating its internal volume into 9 cells with $100 \times 100 \mathrm{~mm}$ in-plane dimensions, and is closed from below by a flat bottom from polished titanium foil, which is connected with the box along the wall and rib end faces by adhesion bonding. The case has flanging for attachment to SV load-carrying shell. As either ceramic or carbon-carbon materials do not allow considerable bending deformations, which arise under the impact of external loads, their fastening is performed through an intermediate element - the damping substrate. The latter should have a certain elasticity and play the role of a soft elastic interlayer (felt), compensating, first of all, all the unevenness of the airframe external metal surface and, secondly, all the bending deformations of the skin, and at the same time, be the emergency thermal protection coating preventing the load-carrying shell from overheating at one tile failure. 


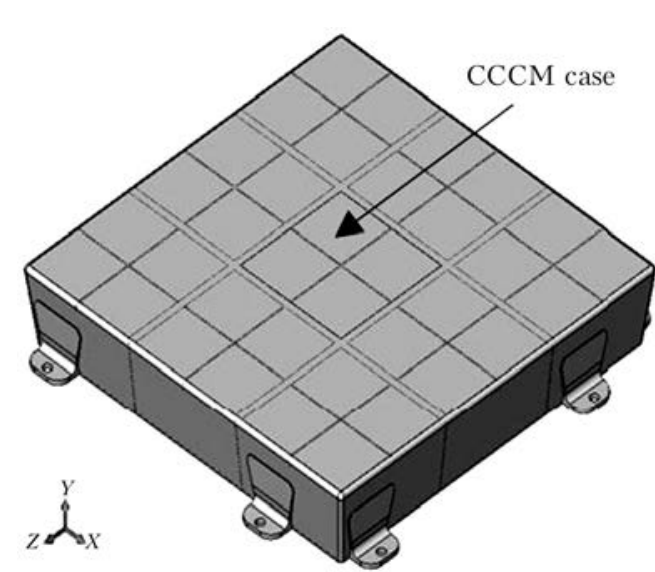

Figure 3. Structure of thermal protection tile with CCCM or ceramic case

The body rests directly on emergency thermal protection coating mounted on SV load-carrying shell, and is fastened in the four corners. Fastening is rigid in one of the corners, and in the other three corners it allows motion in the butt plate in the direction of the straight line connecting this point with the rigidly fastened one. All the fastening points allow rotation in TPS diagonal plane. Tile fastening is performed with screws, which are turned into nuts, fastened on the body of shuttlecraft. Bosses-thermal bridges from glass-reinforced plastic are placed in the zone of screw mounting (Figure 4).

Owing to low coefficients of linear temperature expansion of CCCM and ceramic elements, it is possible to minimize the intertile gaps, in which intertile thermal insulation from quartz fibre, reinforced by quartz cords, is mounted. After that the intertile gaps are closed by a seal from heat-resistant alloy.

Material property values taken for calculation are given in Table 1 . Ni-Cr-based powder alloy - YuIPM-1200 was selected as heat-resistant metal alloy. It was specially developed for application in TPSs of spacecraft. Silicate ceramics with the properties, given in Table 1, was selected for comparison.

External pressure and temperature impact were taken as the main load for design calcula-

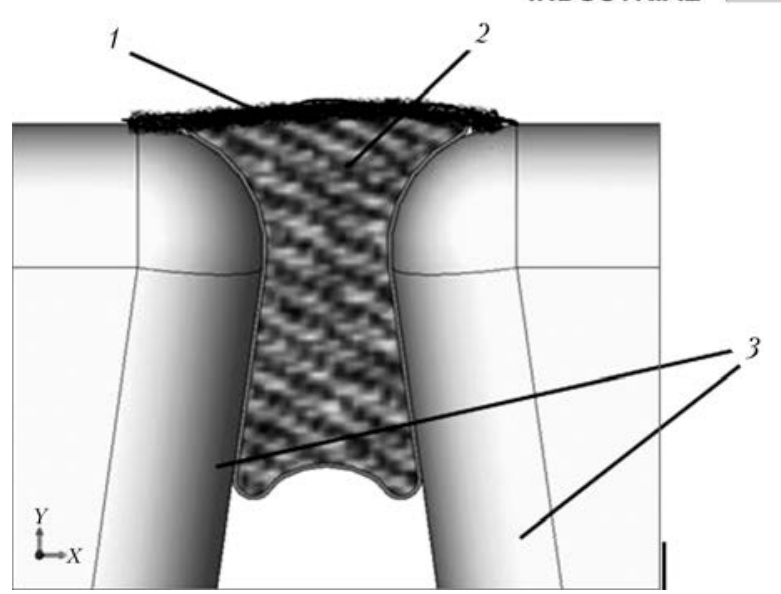

Figure 4. Variant of intertile seal: 1 - seal from heat-resistant alloy; 2 - internal filling of quartz cord type; 3 TPS tile

tions. All the calculations were performed allowing for loading by external calculation pressure of $0.065 \mathrm{MPa}$ at up to $1100{ }^{\circ} \mathrm{C}$ temperatures. In addition, in order to prevent flutter (self-excited non-damping bending and torsional spontaneous vibrations of flying vehicle structural elements, which may lead to its fracture) at maximum dynamic heads in the descent section, the structure was required to have not lower than $100 \mathrm{~Hz}$ frequency of the first tone of spontaneous vibrations.

Selection of the dimensions of the body loadcarrying elements and method of fastening on SV shell was conducted on the basis of analysis of SSS, margins of strength, stability and modal finite element analysis of the respective structure models performed with application of FE packages of Nastran programs.

The load (safety) factor was determined as the ratio of material ultimate strength (critical load for the structure) to maximum stress (calculated load). Structure strength was considered to be sufficient, if the load factor was not less than a unity.

Calculation results are obtained in the form of visualization of each structural element. Results of strength analysis in the case of TPS combined tile are given in Figures 5-9.

Table 1. Physical and mechanical properties of applied materials

\begin{tabular}{|c|c|c|c|c|c|c|}
\hline$T,{ }^{\circ} \mathrm{C}$ & Material & $\rho, \mathrm{g} / \mathrm{cm}^{3}$ & $E, \mathrm{MPa}$ & $\sigma_{\mathrm{b}}, \mathrm{MPa}$ & $\delta, \%$ & $\alpha \cdot 10^{6}, \mathrm{~K}^{-1}$ \\
\hline 20 & \multirow[t]{2}{*}{$\mathrm{CCCM}$} & \multirow[t]{2}{*}{$1.8-2.0$} & \multirow[t]{2}{*}{$24000-45000$} & \multirow{2}{*}{$\frac{90-140}{130-160}$} & \multirow[t]{2}{*}{15} & \multirow[t]{2}{*}{$3.0-4.7$} \\
\hline 1100 & & & & & & \\
\hline 20 & Structure ceramics & 2.4 & 5000 & 50 & - & 5 \\
\hline 20 & \multirow[t]{2}{*}{ YuIPM-1200 alloy } & \multirow[t]{2}{*}{$8.2-8.4$} & & $660-1000$ & 15 & 16 \\
\hline 1100 & & & & 100 & & 21 \\
\hline
\end{tabular}




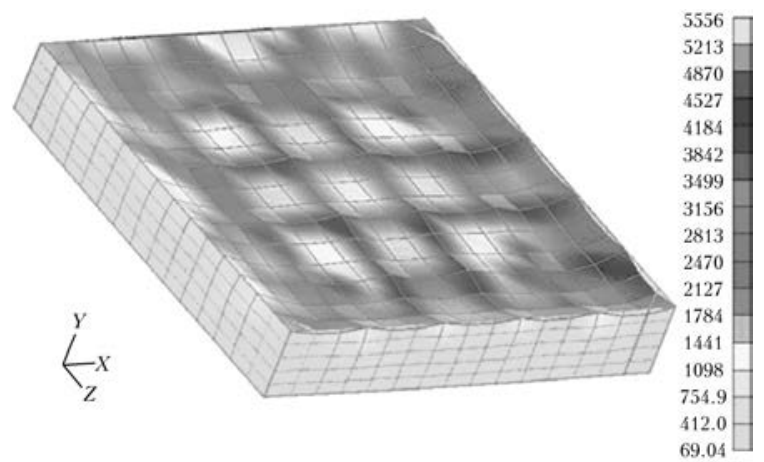

Figure 5. SSS of TPS combined body at loading by $0.065 \mathrm{MPa}$ maximum pressure

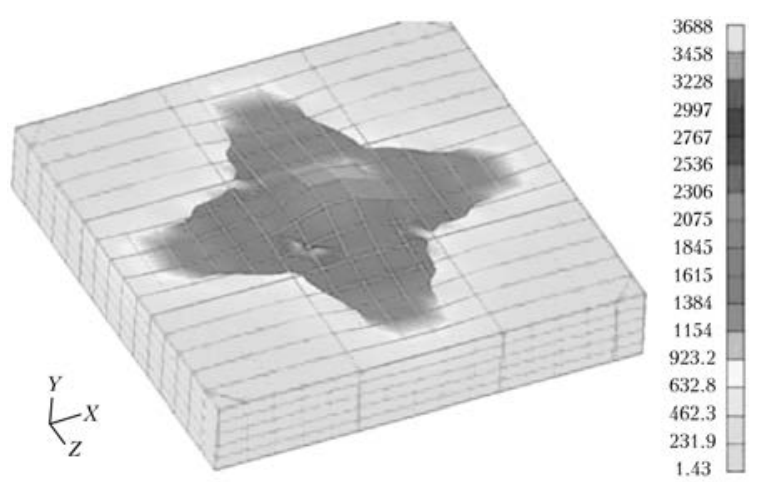

Figure 6. Nature of stability loss of combined body bottom at pressure loading

SSS of TPS tiles at loading by $0.065 \mathrm{MPa}$ pressure is shown in Figures 5 and 6. This structure preserves its stability at loading by external pressure of $0.065 \mathrm{MPa}$, and the external loadcarrying element is the most critical point. Figure 6 gives the nature of stability loss.

Figure 7 shows SSS of TPS tile at temperature loading. Safety factor of the body at temperature loading is equal to 6.12 .

Figure 8 gives the nature of the loss of stability. Frequencies of the first three tones of the body spontaneous vibrations are equal to 294, 302 and $310 \mathrm{~Hz}$ (see Figure 9).

To eliminate flutter, natural frequency should be not lower than $100 \mathrm{~Hz}$, i.e. this structure meets the requirements on flutter resistance. The main results of calculation of the combined tile are given in Table 2 . The structure meets the

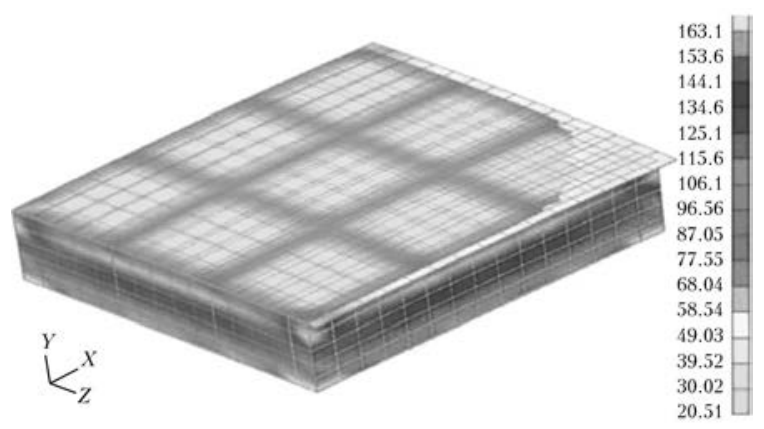

Figure 7. SSS of combined body at temperature loading
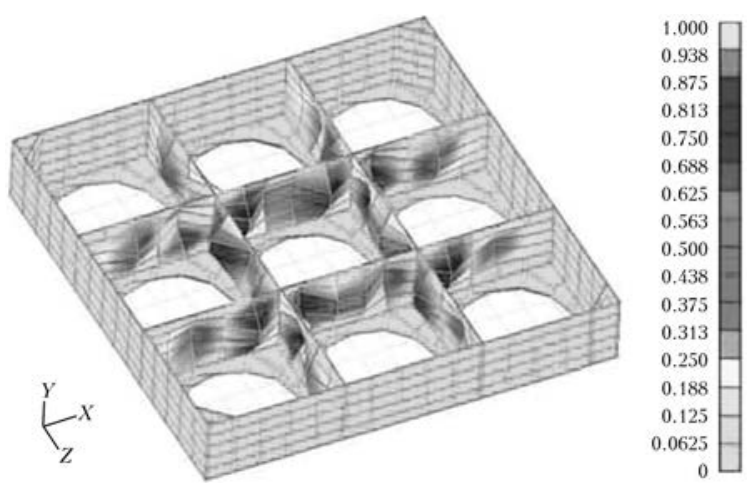

Figure 8. Nature of body stability loss at temperature loading requirements on strength and stability. The mass of this body variant is $670 \mathrm{~g}$. The thickness of the box front sheet contacting RM-1000 plate, is equal to $1 \mathrm{~mm}$, thickness of side walls and ribs is $0.8 \mathrm{~mm}$.

Models of TPS tiles from CCCM and silicate ceramics were analyzed in a similar fashion. The main results of calculations of TPS tiles from CCCM are given in Table 3.

By strength conditions the thickness of box sheet, contacting the environment and directly taking the external loads, is equal to $1.6 \mathrm{~mm}$, thicknesses of side walls and ribs are $0.9 \mathrm{~mm}$. Tile weight is $371 \mathrm{~g}$. Note the quite low deformability of the structure from CCCM, both under the impact of mechanical loads and at heating.

The main results of calculations of TPS tiles from silicate ceramics are given in Table 4. Thickness of box outer sheet, taking up external loads, is equal to $2 \mathrm{~mm}$, thickness of side walls and ribs is $1 \mathrm{~mm}$. Body weight is $920 \mathrm{~g}$.

Analysis of calculation results. Calculation results enable determination of the dimensions of load-carrying elements of TPS combined tiles and CCCM and ceramic tiles, which meet the requirements to strength, stability and flutter resistance, and weight of each structure (Table 5). Thermal protection tile with CCCM body has the best weight and strength characteristics. Body weight is $371 \mathrm{~g}$, load factor is 1.16 , first

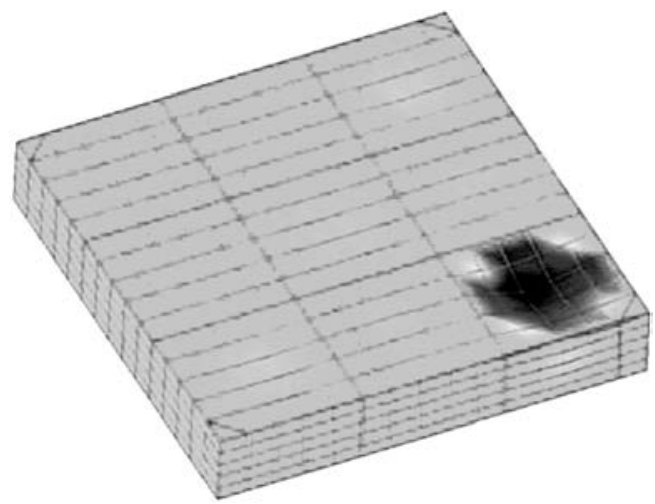

Figure 9. Shape of the first tone of natural vibrations of combined body 
Table 2. Results of combined tile calculations

\begin{tabular}{|c|c|c|c|c|c|c|}
\hline Parameter & Studied factor & $\sigma_{\max }, \mathrm{MPa}$ & $V_{\max }, \mathrm{mm}$ & $W_{\max }, \mathrm{mm}$ & $\eta$ & $F, \mathrm{~Hz}$ \\
\hline \multirow[t]{2}{*}{ Calculated pressure } & $\begin{array}{c}\text { Strength } \\
\text { CCCM } \\
\text { YuIPM-1200 }\end{array}$ & $\begin{array}{c}85.4 \\
215.5\end{array}$ & 0.59 & 2.68 & 1.05 & - \\
\hline & Stability & - & - & - & 1.08 & - \\
\hline \multirow[t]{2}{*}{ Temperature loading } & $\begin{array}{c}\text { Strength } \\
\text { CCCM } \\
\text { YuIPM-1200 }\end{array}$ & $\begin{array}{c}11.1 \\
9 \\
\end{array}$ & 4.73 & 1.50 & $>>1$ & - \\
\hline & Stability & - & - & - & 6.12 & - \\
\hline \multirow[t]{3}{*}{ Frequency analysis } & Sample 1 & - & - & - & - & 294 \\
\hline & Sample 2 & - & - & - & - & 302 \\
\hline & Sample 3 & - & - & - & - & 310 \\
\hline
\end{tabular}

Table 3. Results of CCCM tile calculations

\begin{tabular}{||c|c|c|c|c|c|c|c||}
\hline \hline Parameter & Studied factor & $\sigma_{\mathrm{b}}, \mathrm{MPa}$ & $\sigma_{\max }, \mathrm{MPa}$ & $V_{\max }, \mathrm{mm}$ & $W_{\max }, \mathrm{mm}$ & $\eta$ & $F, \mathrm{~Hz}$ \\
\hline \multirow{2}{*}{ Calculated pressure } & Strength & 90 & 70.3 & 0.40 & 1.40 & 1.28 & - \\
\cline { 2 - 9 } & Stability & - & - & - & - & 1.16 & - \\
\hline \multirow{2}{*}{ Temperature loading } & Strength & 130 & 10.7 & 0.63 & 1.48 & 12.10 & - \\
\cline { 2 - 9 } & Stability & - & - & - & - & 36.60 & - \\
\hline \multirow{2}{*}{ Frequency analysis } & Sample 1 & - & - & - & - & - & 742 \\
\cline { 2 - 9 } & Sample 2 & - & - & - & - & - & 762 \\
\cline { 2 - 9 } & Sample 3 & - & - & - & - & - & 808 \\
\hline
\end{tabular}

Table 4. Main results of calculations of TPS tile from silicate ceramics

\begin{tabular}{||c|c|c|c|c|c|c|c||}
\hline \hline Parameter & Studied factor & $\sigma_{\mathrm{b}}, \mathrm{MPa}$ & $\sigma_{\max }, \mathrm{MPa}$ & $V_{\max }, \mathrm{mm}$ & $W_{\max }, \mathrm{mm}$ & $\eta$ & $F, \mathrm{~Hz}$ \\
\hline \multirow{2}{*}{ Calculated pressure } & Strength & 50 & 27.8 & 0.85 & 4 & 1.80 & - \\
\cline { 2 - 9 } & Stability & - & - & - & - & 2.38 & - \\
\hline \multirow{2}{*}{ Temperature loading } & Strength & 50 & 25.2 & 1.1 & 0.23 & 1.98 & - \\
\cline { 2 - 9 } & Stability & - & - & - & 1.03 & 1.03 & - \\
\hline \multirow{2}{*}{ Frequency analysis } & Sample 1 & - & - & - & - & - & 271 \\
\cline { 2 - 9 } & Sample 2 & - & - & - & - & - & - \\
\cline { 2 - 9 } & Sample 3 & - & - & - & - & -293 \\
\hline
\end{tabular}

Table 5. Calculated values of tile parameters

\begin{tabular}{||l|c|c|c||}
\hline \multicolumn{1}{|c|}{ Material, structure type } & Weight, $\mathrm{g}$ & Load factor & $F, \mathrm{~Hz}$, at $T=20^{\circ} \mathrm{C}\left(1000{ }^{\circ} \mathrm{C}\right)$ \\
\hline CCCM & 371 & 1.16 & $742(742)$ \\
\hline Structure (silicate) ceramics & 920 & 1.03 & $271(271)$ \\
\hline YuIPM-1200, base with sheet load-carrying element & 1100 & 1.03 & $246(54)$ \\
\hline Same, base with three-layer corrugated panel & 760 & 1 & $219(48)$ \\
\hline Same, base with three-layer honeycomb panel & 612 & 1.17 & $428(94)$ \\
\hline Combined tile from CCCM and YuIPM-1200 & 670 & 1.05 & $294(64)$ \\
\hline
\end{tabular}


tone frequency at 20 and $1000{ }^{\circ} \mathrm{C}$ is equal to $742 \mathrm{~Hz}$. However, CCCM tiles require special protection of the external surface from loss at high temperatures, as well as development of cost-effective technologies of manufacturing thin-walled structures, that is practically impossible to implement at the modern level of engineering development.

Weight of thermal protection tile with external three-layer honeycomb panel from YuIPM1200 alloy is equal to $612 \mathrm{~g}$, that, even though it is higher than that of tile with CCCM body, still allows application of this structure for development of TPS of future shuttlecrafts. Here, an extremely important fact is the availability of extensive experience of manufacturing metal structures allowing development of technology of manufacturing tiles with external three-layer honeycomb panel. The main objective is manufacturing heat-resistant three-layer honeycomb panel. Adhesion joints do not ensure reliable operation of the structure in the service temperature range, therefore, it is necessary to develop the technology of manufacturing the honeycomb core by welding and its joining with panel skins.

Experimental studies showed that the honeycomb core can be made by welding the separate strips by passing current. The most complex task is welding the honeycomb core to the skins.

Such technologies for heat-resistant welded structures are developed at PWI.

The variant of thermal protection tiles with the combined body, having an external metal panel from YuIPM-1200 alloy and box made from CCCM, also looks promising. The weight of such a body is $670 \mathrm{~g}$, however, its practical implementation requires development of the technology of manufacturing thin-wall body from CCCM and technology of its welding to metal.

The weight of thermal protection tile with ceramic bodies is higher, and the load factor is lower, so that these structures are not attractive for application in thermal protection of future shuttlecrafts.

\section{Conclusions}

1. Influence of mechanical and thermal loading on thermal protection tiles with different loadcarrying layers from heat-resistant materials and packs of inner thermal insulation has been studied. It is found that thermal protection tiles with the body of CCCM and tiles with external threelayer honeycomb panel from YuIPM-1200 alloy have the best weight and strength characteristics.

2. Thermal protection tiles of CCCM require special protection of external surface from loss at high temperatures, as well as development of technologies of manufacturing thin-walled structures that makes them not cost-effective at present. Therefore, the most promising are the TPSs with external three-layer honeycomb panel from YuIPM-1200 alloy, which is resistant in oxidizing medium at service temperatures. Available experience of manufacturing metal products and their joining by various welding, as well as costeffectiveness of such technologies, should be also taken into account.

1. Gofin, M.Ya. (2003) Heat-resistant and thermal protection structures of shuttlecrafts. Moscow: Mir.

2. Koleda, V.V., Polozhaj, S.G., Potapov, A.M. et al. (2007) Thermal protection elements for shuttlecrafts. In: Proc. of 1st Int. Conf. on Advanced Space Technologies for Benefit of Mankind (18-20 April 2007, Dnepropetrovsk, Ukraine).

3. Tretiakov, Yu.D. Ceramics in the past, present and future. http:// www.pereplet.ru

4. Krenkel, W. (2008) Ceramic matrix composites. Weinheim: Wiley-VCH.

5. Glass, D.E., Capriotti, D.P., Reimer, T. et al. (2013) Testing of DLR C/C-SiC for HIFiRE \& Scramjet Combustor. In: Proc. of 7th Europ. Workshop on Thermal Protection Systems and Hot Structures (8-10 April 2013, Noordwijk, The Netherlands).

6. Tikhy, V.G., Gusev, V.V., Potapov, A.M. et al. (2014) Prospective thermal protection structure of shuttlecrafts with metal load-carrying element. In: Transact. of N.E. Zhukovsky NAU on Problems of Design and Production of Flying Vehicles, 28-43. Kharkov: KhAI.

Received 05.02.2015 